\title{
Repensando la participación de las mujeres en el desarrollo desde una perspectiva de género
}

\section{Sònia Parella Rubio}

Universitat Autònoma de Barcelona. Departament de Sociologia sonia.parella@uab.es

\section{Resumen}

Este artículo revisa los principales enfoques teóricos en el estudio del desarrollo desde una perspectiva de género; con el fin de analizar cómo ha ido evolucionando el tratamiento que desde ellos se ha dado a las relaciones de género y cuáles son los instrumentos conceptuales que deben utilizarse para abordar en su globalidad el papel que desempeña la mujer en el desarrollo.

Palabras clave: género, desarrollo, globalización.

\section{Abstract: Revising Participation of Women in Development from a Gender Perspective}

This article revises the main theoretical approaches in the study of development from a gender perspetive. The author examines how these approaches explain gender relations and which are the suitable conceptual instruments to deal with the role that play women in development.

Key words: gender, development, globalization.

\section{Sumario}

Introducción

1. Síntesis de las principales teorías sobre el desarrollo en un contexto histórico 2. Mujeres y desarrollo: una revisión teórica
3. La participación de las mujeres en el desarrollo

4. Conclusiones

Bibliografía

\section{Introducción}

El predominio del discurso de la mujer como económicamente inactiva, tanto desde la academia como desde las representaciones sociales, también se ha extendido a las teorías sobre el desarrollo. En la mayor parte de los estudios del desarrollo, y por ende en los programas y proyectos que de ellos se derivan, aun cuando el trabajo y los ingresos de las mujeres resultan indispensables para la supervivencia familiar, sólo se reconoce su rol reproductivo como 
contribución a la sociedad; mientras que sus actividades productivas permanecen ocultas y no se toma en cuenta la influencia decisiva que ejerce el género en la configuración total de las relaciones de producción. La categoría género es un término esencial para comprender el desarrollo en todas sus dimensiones, ya que revela aspectos básicos en la organización de la producción y en el trabajo, entendido en su acepción más amplia, que incluye tanto el trabajo remunerado como el trabajo doméstico o no remunerado. Las estrategias de desarrollo capitalista a nivel mundial han tenido efectos altamente diferenciados entre hombres y mujeres (Fernández-Kelly, 1991). Poner el acento sobre el papel activo de las mujeres en el desarrollo es el principal objetivo de este artículo.

A lo largo de estas páginas se ofrece una breve exposición de los principales enfoques teóricos en el estudio del desarrollo desde una perspectiva de género, con el fin de analizar cómo ha ido evolucionando el tratamiento que desde ellos se ha dado a las relaciones de género y al papel que desempeña la mujer. Dicho recorrido nos conduce a la necesidad de articular las relaciones de producción y de reproducción para comprender el papel activo y específico de las mujeres como agentes de desarrollo. Los estudios sobre el desarrollo deben enmarcarse dentro del proceso globalizador actual, un proceso que da forma y refuerza las dinámicas de desigualdad y dependencia entre los países pobres y ricos a través del sistema de producción capitalista. La globalización tiene un impacto claramente diferenciado según género, de modo que las mujeres de los países pobres o periféricos son las principales perdedoras, resultado de la yuxtaposición de su posición subordinada en el sistema económico mundial y de su condición de mujer, en el contexto de las relaciones patriarcales. Partiendo de este marco teórico, el artículo finaliza con una panorámica que recoge las principales contribuciones de las mujeres al desarrollo, tanto en la esfera reproductiva como productiva; poniendo especial énfasis en el reclutamiento de mujeres como fuerza de trabajo asalariada para las industrias para la exportación en los países periféricos. De dicha contribución se desprende que la mujer tiene un papel cada vez más esencial en las estrategias de supervivencia que despliegan las familias y las comunidades en los países menos desarrollados (Sassen, 2000; Ribas, 2001).

\section{Síntesis de las principales teorías sobre el desarrollo en un contexto histórico}

Los distintos enfoques sobre el desarrollo pretenden dilucidar las causas teóricas de la desigualdad a escala planetaria, así como las estrategias necesarias para reducirlas. Difieren entre sí, principalmente, respecto al carácter exógeno o endógeno de los factores de desarrollo y, en base a este criterio, pueden agruparse en torno a dos grandes enfoques confrontados: el de la modernización y el de la dependencia. El enfoque de la modernización ${ }^{1}$, como modelo de

1. A lo largo de estas páginas se utiliza el concepto «modernización» desde la perspectiva económica que se origina en las décadas de 1950 y 1960 y que se basa en la concepción fun- 
desarrollo económico y social, surge en las décadas de 1950 y 1960, cuando el concepto «modernización» es muy popular en el ámbito occidental. Se trata de un enfoque teórico que deriva del paradigma de la economía clásica y de las perspectivas sociológicas funcionalistas. Tal marco teórico sostiene que la desigual distribución de la riqueza en el mundo puede ser explicada en función de los distintos niveles de desarrollo tecnológico que han alcanzado las sociedades. En este sentido, el crecimiento económico se asocia a los procesos de industrialización y urbanización, de modo que las economías de subsistencia (sector «tradicional») deben transformarse en un sistema comercializado de economía nacional («sector capitalista moderno»), hasta llegar a convergir en el modelo occidental de desarrollo. Dicho proceso entraña un progresivo descenso de la fuerza de trabajo ocupada en la agricultura, que es absorbida por la industria y los servicios, una creciente demanda de fuerza de trabajo especializada y una mayor división del trabajo ${ }^{2}$ (Solé, 1998). La migración de mano de obra del campo a las ciudades es el principal mecanismo que permite el crecimiento y el desarrollo. Sin embargo, estas predicciones han sido puestas en entredicho, al constatarse la fuerte concentración de excedente de mano de obra en las ciudades, hacinada en los núcleos urbanos bajo condiciones de extrema pobreza y sobreviviendo en la economía informal (Wood, 1992).

Los teóricos de la modernización enfatizaron la necesidad de transferencia de patrones culturales, políticos y económicos de países industrializados a países considerados «subdesarrollados», con la expectativa de que tal transferencia generaría riqueza y prosperidad en los últimos. En definitiva, en tanto que esta perspectiva atribuye las causas teóricas de la desigualdad mundial a factores endógenos, se «culpabiliza» a los países pobres de su situación y se anima a los países ricos a desempeñar un papel fundamental en el proceso de desarrollo económico a escala mundial ${ }^{3}$. Para la perspectiva de la modernización, las

cionalista de «modernización» para explicar las causas del desarrollo. Se trata de un planteamiento etnocéntrico, que restringe la "modernización" a las sociedades que siguen el modelo occidental de cambio social. Sin embargo, desde la sociología y la antropología existen otras nociones de "modernización", que en este artículo no se toman en cuenta: la antropológica, la marxista, ecológica, reflexiva, etc. Para un análisis profundo sobre los distintos enfoques teóricos que han utilizado el concepto «modernización» y sobre sus connotaciones ideológicas, véase Solé (1998).

2. Lewis (1969), en su influyente modelo de los dos sectores, postula que en los países en vías de desarrollo coexiste un sector capitalista «moderno» (empresas multinacionales y grandes plantaciones con mano de obra asalariada) junto a un sector "tradicional», compuesto por empresas individuales y familiares y no regido por reglas de funcionamiento económico capitalistas. Para LEWIS, dicho dualismo es positivo y constituye una etapa necesaria dentro del proceso de desarrollo, puesto que el sector "tradicional» cumple la función de fuente inagotable de mano de obra para el sector «moderno».

3. Según estos teóricos, las sociedades ricas contribuyen a aliviar la desigualdad a través de cuatro formas distintas: ayudas para el control demográfico, aumento de la capacidad de producción de alimentos (revolución agrícola), introducción de la tecnología industrial y programas de ayuda al desarrollo (Macionis, Plummer, 2000). 
tradiciones culturales constituyen el mayor impedimento al proceso de desarrollo, puesto que éstas pueden constituir un freno a la industrialización y a la penetración de los avances tecnológicos ${ }^{4}$.

Durante las décadas de 1940 y 1950, las teorías de la "modernización» predominaron en los estudios sobre desarrollo y muchos de sus postulados siguen todavía vigentes en la actualidad. Con la llegada de la década de los sesenta se asiste a planteamientos diametralmente opuestos, desde enfoques estructuralistas y neomarxistas. Teóricos como Gunder Frank (1967), Cardoso y Faletto (1969) y Amin (1974) denuncian la falacia que sostiene que los actuales países pobres siempre lo han sido y deben «imitar» a Occidente para alcanzar el desarrollo. Por el contrario, estos autores, conocidos como teóricos de la dependencia, argumentan que muchas sociedades antes prósperas, son ahora subdesarrolladas como resultado de la intervención de los intereses imperialistas en su economía. Los países ricos, lejos de ayudar a resolver el problema de las desigualdades a escala mundial, lo que hacen es reproducirlas; puesto que el imperialismo refuerza la dualidad existente entre sociedades ricas y pobres. Si no se hubiera dado el período de colonización, el despegue económico inicial de Europa no habría sido posible; por lo que la desigualdad en el mundo se debe a pautas históricas de explotación de los países pobres por los países ricos. En contraste con la teoría de la modernización, los teóricos de la dependencia superan el enfoque etnocéntrico que equipara "desarrollo" y occidentalización y desplazan la atención de las características internas de la economía nacional hacia las relaciones estructurales de explotación, históricamente determinadas, en un contexto mundial en mutación (Wood, 1992).

Las estructuras económicas y sociales tradicionales, lejos de ser un obstáculo para el desarrollo, tal como propugnan los teóricos de la modernización, se transforman en estructuras "subdesarrolladas» una vez entran en contacto con el sistema económico capitalista (Amin, 1974). El propio subdesarrollo no es la consecuencia del aislamiento de las sociedades con respecto a la expansión del capitalismo, sino que es justamente el resultado de su incorporación en él. Por lo tanto, existe una contradicción interna esencial dentro del capitalismo entre países explotadores y países explotados; de manera que el atraso de ciertas áreas del mundo es el efecto y a la vez la condición del desarrollo en otras partes del mundo. El sistema capitalista, contextualizado a nivel internacional y no como suma de capitalismos nacionales, tiene una estructura de metrópolis-satélites o centro-periferia, en la que se inscriben las economías del sistema (Gunder Frank, 1991). Los países del centro explotan y se apropian del excedente económico de los países periféricos, mediante la inversión de capitales a escala mundial, lo que genera desarrollo en los primeros y subdesarrollo en los últimos.

4. El ejemplo más claro de la relación entre los valores culturales y el proceso de desarrollo lo constituye el «espíritu calvinista» que favoreció la llegada de la revolución industrial en Europa central. 
A partir de los años setenta, el enfoque basado en los sistemas mundiales, representado por Wallerstein (1979), da un paso más en la conceptualización del desarrollo y define el «sistema-mundo" como un sistema social formado por regiones geográficas que tienen funciones diferentes y desiguales dentro de la división global del trabajo. De ese modo, la estructura del sistema-mundo capitalista gira en torno a una división social del trabajo que muestra la emergencia de una tensión entre un centro, una semiperiferia y una periferia, basada en el intercambio desigual. Mientras el centro está integrado por las formaciones sociales con un desarrollo capitalista autónomo, articulado y autocentrado, la periferia está constituida por formaciones sociales con un desarrollo capitalista inducido desde fuera - primero por la colonización y más tarde por las multinacionales_- Ello ha dado lugar a sociedades desarticuladas, no diversificadas, que aseguran una tasa de beneficio elevado al capital a través de las exportaciones baratas y la explotación de una mano de obra que recibe salarios muy bajos. De acuerdo con el autor, la economía mundial impone a los países pobres del mundo una relación de dependencia con respecto a los países ricos, situación que refuerza todavía más el endeudamiento externo. El subdesarrollo es visto como el resultado de la expansión de la economía-mundo capitalista - proceso originado en Europa occidental hace quinientos años-— que, a tenor de su lógica intrínsecamente global, va integrando progresiva e ineludiblemente las distintas zonas del planeta. Todo el mundo, sin excepción, opera dentro del marco y las reglas del sistema económico capitalista. La aportación de Wallerstein, a diferencia de los teóricos de la dependencia, deja de lado el Estado-nación y las unidades espaciales diferenciadas y toma como unidad de análisis el sistema mundial ${ }^{5}$.

Finalmente, debe señalarse también otra perspectiva que examina el surgimiento de una nueva división del trabajo a nivel internacional (Fröbel y otros, 1981; Nash y Fernández-Kelly, 1983). Tal enfoque parte de los cambios profundos que han acontecido en el sistema mundial de producción y de la competencia a nivel internacional que ha llevado a las empresas multinacionales a trasladar operaciones manufactureras de países avanzados a países menos desarrollados, con el objeto de reducir costos de producción y socavar los logros de los sindicatos en países industrializados. La nueva división internacional del trabajo ha sido acompañada por una marcada preferencia por la contrata-

5. Autores como Zolberg (1983: 9-10) han criticado duramente el enfoque de los sistemas mundiales por subestimar la estructura política y considerar que los estados son meros instrumentos de la dinámica capitalista. De ese modo, es la localización de cada sociedad en cada uno de los segmentos la que determina el tipo de organización política, constituyéndose un estado fuerte en el centro capitalista y débil en la periferia. Según Zolberg, los determinantes económicos y políticos están íntimamente relacionados, ya que desde la aparición del Estado como forma de organización política, éste ha interaccionado con las fuerzas generadas por el capitalismo. En este sentido, el autor constata que la resistencia de una organización política a la entrada del capitalismo - tal como ha ocurrido en los países socialistas - desempeña un rol determinante en la ubicación de una sociedad en el centro o bien en la periferia. 
ción de mujeres en las líneas de ensamblaje y otras operaciones industriales, tal como se verá más adelante. Las relaciones patriarcales, es decir, los patrones culturales de dominación masculina, son aprovechadas por el capitalismo para lograr una mayor docilidad y un menor coste de la fuerza de trabajo.

Durante la primera mitad del siglo XX, la División Internacional del Trabajo (DIT) se articula en Europa, Estados Unidos y Japón (centro capitalista) en torno a la industria de transformación, mientras que en algunos enclaves de América Latina, África y Asia (periferia capitalista) se producen materias primas para la exportación y se vinculan de forma dependiente a la economía mundial. Con el proceso de globalización de las economías y la tendencia a la desaparición de las fronteras económicas entre los países, se asiste a una fuerte movilidad del capital. Ésta se traduce, durante la década de los setenta, en la transferencia de gran parte de la producción industrial de trabajo intensivo (textil, juguetes, confección, electrónica, etc.) desde los países industrializados hacia países de salarios bajos, con escasas e insuficientes regulaciones laborales y productivas y con una abundante oferta de fuerza de trabajo barata. Las etapas del proceso productivo que se transfieren a otros países son las más intensivas en fuerza de trabajo, con procesos productivos estandarizados y repetitivos, muy costosos de mecanizar (Bifani, 1997). Se asiste a una Nueva División Internacional del Trabajo (NDIT), consistente en la fragmentación del proceso productivo en fases de producción que permiten la «deslocalización industrial» en países periféricos, gracias a la reducción de las barreras naturales y arancelarias al comercio internacional (Groizard, 1996). Los agentes de este nuevo modelo de inversión directa extranjera son las empresas transnacionales (ETN) y sus redes asociadas, por cuanto difunden las relaciones capitalistas por todo el mundo, imponen las orientaciones del cambio tecnológico y organizativo, a la vez que condicionan las políticas económicas de los gobiernos y la actividad competitiva ${ }^{6}$ (Groizard, 1996).

La fragmentación y relocalización del proceso industrial permite a las empresas multinacionales beneficiarse de la existencia de mano de obra barata, ya sea creando nuevas sucursales en la periferia, o bien subcontratando a medianas y pequeñas empresas ya existentes, a menudo en el sector informal ${ }^{7}$. Los procesos de "deslocalización» y de mejora de la competitividad mediante dumping social generan, por lo general, empleos de menor calidad que el empleo industrial que desaparece en los países del centro; al tratarse de puestos de trabajo poco cualificados, escasamente "formalizados» y sin una aplicación intensiva de los avances tecnológicos y los parámetros organizativos propios de las sociedades más avanzadas (Tezanos, 2001). En cualquier caso, el potencial

6. Las 200 corporaciones más grandes del planeta están controladas por 150 personas y se localizan en su mayor parte en cinco países: EEUU, Alemania, Francia y Reino Unido (Tezanos, 2001: 43).

7. Los procesos de flexibilización y precarización del mercado de trabajo, así como la desregulación de la actividad económica en los países del centro, se enmarcan dentro de la misma tendencia de reducción de costes (Lim, 1983; Benería, 1991; Castells, 1997). 
dinamizador de la «deslocalización» en la periferia es mínimo, puesto que se trata de enclaves que no mantienen vínculos con las economías de los países del centro. Son las empresas madre, situadas en el centro, las que comercializan los productos y mantienen un control absoluto sobre el mercado.

\section{Mujeres y desarrollo: una revisión teórica}

La literatura científica sobre género y desarrollo ha evolucionado de manera autónoma, aunque se ha visto directamente condicionada por los planteamientos y por la ignorancia del papel de la mujer en las distintas teorías del desarrollo general (Portes, 1991). A la hora de explicar la ausencia de las mujeres en los estudios sobre desarrollo, deben tenerse en cuenta una serie de factores. En primer lugar, el predominio del discurso de la mujer como económicamente inactiva, tanto desde la academia como desde las representaciones sociales. Otro aspecto a tener en cuenta es el alto nivel de abstracción de los estudios sobre desarrollo socioeconómico y su preferencia por los datos cuantitativos, lo que ha ocultado una serie de diferencias entre hombres y mujeres que sólo pueden ser percibidas a través de la investigación de campo. De hecho, han sido justamente las antropólogas sociales las que han introducido la importancia de las diferencias sexuales en el desarrollo. Por último, el carácter contestatario del feminismo ha provocado que en los círculos conservadores, tanto académicos como políticos, se haya considerado el activismo a favor de las mujeres como una amenaza a las estructuras de poder económico y social establecidas (Fernández-Kelly, 1991).

La tesis implícita en las teorías de la modernización es que el cambio social es un proceso neutral respecto de la condición de mujeres y hombres. Las políticas de desarrollo con respecto a las mujeres durante los años cincuenta y sesenta tienen mucha relación con los esfuerzos de los colonizadores occidentales por reforzar la dominación masculina, de manera que se va introduciendo la división entre espacio «masculino» $\mathrm{y}$ «femenino» implantada en Europa (Hernández, 1999). Para el paradigma de la modernización se contraponen claramente los procesos de urbanización e industrialización, dominados por los hombres, con la vida rural y el sector privado, considerados espacios propios de las mujeres. Este antagonismo es el responsable de la invisibilidad del papel de la mujer, ya que se la asocia al hogar y, por consiguiente, a los valores tradicionales y conservadores de la familia y de la comunidad. Pero, contrariamente a lo que sostienen los planteamientos de este enfoque, la coexistencia de dos modos de producción —el de subsistencia y el capitalista- no se produce como si se tratara de dos sectores separados e independientes; sino que el sector capitalista depende del de subsistencia para su perpetuación y, en éste último, el papel de las mujeres es esencial (Benería, 1981: 74).

Bajo el prisma de las teorías de la modernización, el pionero enfoque del bienestar — que aparece en los años cincuenta y sesenta y sigue todavía hoy vigente en algunos debates - es un fiel reflejo del modelo de industrialización occidental de la época, basado en una división sexual del trabajo que colo- 
ca al hombre en la esfera productiva y relega a la mujer a su papel de ama de casa. Este enfoque pretende, por un lado, fomentar la capacidad productiva masculina y, por el otro, ayudar a satisfacer las necesidades de las familias, a través de dirigir la ayuda para el bienestar a las mujeres, a modo de «correas de transmisión» hacia el resto de miembros de la familia (alimentación, salud, planificación familiar, etc. $)^{8}$ (Hernández, 1999). Durante este período, los programas de desarrollo identifican acríticamente a la mujer en su rol reproductivo y la convierten en beneficiaria pasiva de los programas asistenciales en calidad de madres, considerando que estas acciones son fundamentales no sólo para la mujer, sino básicamente para el desarrollo económico del conjunto de la sociedad. En este sentido, puede concluirse que el enfoque del bienestar asume que la mujer es receptora pasiva del desarrollo, sin autonomía y derechos, y que su rol principal se sitúa en la esfera reproductiva (Zabala, 1999; Massolo, 1999).

La ignorancia del papel activo de la mujer en el Tercer Mundo se supera, en parte, con los análisis de la economista Esther Boserup (1970), con su obra titulada El papel de la mujer en el desarrollo económico. Boserup demuestra que los planificadores del desarrollo habían actuado siempre bajo supuestos estereotipados sobre las mujeres: la subestimación de su rol productivo y la equiparación del trabajo de las mujeres a las tareas de reproducción y cuidados. La autora, aceptando la dinámica de la acumulación capitalista y la necesaria expansión del mercado como algo positivo, argumenta que los procesos de desarrollo han marginado a la mujer de forma sistemática, en base a la división sexual del trabajo. Refiriéndose a la situación de los años sesenta en el Tercer Mundo, concluye que el desarrollo de la gran industria provoca la pérdida de trabajo de las mujeres; puesto que los productos artesanales que ellas fabricaban en el seno de la industria familiar son reemplazados por productos de fábrica que han sido producidos por una mano de obra predominantemente masculina. Ante esta situación, las mujeres sólo pueden recurrir al sector informal - especialmente al servicio doméstico- en las ciudades (Boserup, 1970: 111).

Boserup (1970) considera determinante la participación de las mujeres en las actividades económicas para explicar su estatus social; por lo que concluye que la modernización, en la medida que reduce esta participación, ha tenido un efecto perjudicial para la mujer de las zonas rurales. La perspectiva de esta autora se sustenta en la convicción de que las desigualdades sociales de carácter sexual son el resultado de la expulsión de las mujeres del sistema productivo, como consecuencia de las imperfecciones de la implantación del proceso de modernización, responsables de distorsionar los patrones tradicionales de reciprocidad entre hombres y mujeres (Fernández-Kelly, 1991). Boserup ofrece

8. La propia OIT (Organización Internacional del Trabajo), sin ir más lejos, menciona el papel de las mujeres en la satisfacción de las necesidades básicas y pone de manifiesto la conveniencia de mejorar su capacitación para que contribuyan de manera más eficaz a cumplir con el papel tradicional que les corresponde (González, 2001). 
las bases para el enfoque llamado $\mathrm{MED}^{9}$, Mujer en el Desarrollo, movimiento que surge en los años setenta y que plantea abordar el impacto negativo que el desarrollo está teniendo sobre las mujeres. El primer objetivo de esta corriente es lograr la visibilidad de las mujeres como categoría en las investigaciones y en las políticas de desarrollo, con el fin de eliminar su marginación de los procesos de desarrollo en beneficio de los hombres. Por primera vez se afirma que la posición subordinada de la mujer es un obstáculo para el desarrollo, aunque siguen sin cuestionarse los postulados del enfoque de la modernización (Afshar, 1999; Luna, 1999).

Sin embargo, siguiendo la tipología que propone Ajamil (1999), los planteamientos del enfoque MED no son estáticos, sino que han ido evolucionando. En un primer momento, como contrapartida al enfoque del bienestar, se da un extraordinario énfasis al logro de la independencia económica de las mujeres como sinónimo de reducción de la desigualdad entre hombres y mujeres — enfoque de la equidad y enfoque de la antipobreza- El interés se focaliza, por consiguiente, en la participación de las mujeres en la esfera productiva y se deja de lado tanto el trabajo reproductivo como las relaciones entre ambas esferas (Zabala, 1999). Más adelante, en el contexto de crisis económica global y de las medidas de ajuste estructural de la década de los ochenta, aparece una nueva tendencia —enfoque de la eficiencia-, que desplaza el punto de mira hacia el rol reproductivo de las mujeres y la importancia del trabajo gratuito que realizan para el desarrollo del conjunto de la sociedad.

Tanto Boserup (1970) como el enfoque MED han recibido duras críticas desde el marxismo feminista. No puede obviarse que los planteamientos de Boserup dan un impulso fundamental al debate acerca de los efectos del desarrollo sobre la mujer en el Tercer Mundo. Sin embargo, la autora sólo toma en consideración las repercusiones que la industrialización y la imposición de cultivos tienen para el estatus de la mujer agricultora en el contexto de las sociedades patriarcales; pero no incluye en su análisis la dimensión de la clase social. En este sentido, no es que la mujer no participe en el proceso de desarrollo, sino que está integrada en él. Por lo tanto, si bien es cierto que con la entrada de capital la mujer pierde control sobre los recursos económicos en calidad de productora artesanal, Boserup no tiene en cuenta la fuerte preferencia que ha tenido el capital por las mujeres jóvenes para que trabajen de asalariadas en las industrias multinacionales, en las escalas más bajas de la estructura ocupacional y en trabajos mal remunerados e inestables (Benería, Sen, 1983).

Por lo tanto, el sistema capitalista hace uso de las desigualdades de género existentes y ubica a la mujer en posiciones subordinadas a distintos niveles de interacción entre la clase social y el género. Lo que debe discutirse no es tanto

9. El enfoque MED tuvo su escenario más visible en la I Conferencia Mundial de la Mujer (México 1975) y desde la década de los setenta ha sido el enfoque más influyente (Luna 1999: 66). 
la participación o no de la mujer en el desarrollo, sino su forma de integración en el mismo. Benería y Sen (1983: 110) argumentan que el papel de la mujer en el desarrollo tiene que estudiarse a partir de la conexión existente entre las desigualdades de género y de clase, puesto que son las mujeres pobres las más oprimidas por el capitalismo. Esta constatación permite superar tanto el enfoque funcionalista de la modernización, que ignora ambas dimensiones, como el enfoque de la dependencia, que focaliza su atención tan sólo en la dimensión de clase. Los teóricos de la dependencia y de los sistemas mundiales basan sus argumentaciones en las relaciones de subordinación entre el centro y la periferia y defienden, siguiendo los esquemas de la teoría marxista, que la dominación del hombre sobre la mujer se supera mediante la transformación de las relaciones sociales de producción. Estos teóricos consideran que la solución a la opresión de la mujer se encuentra en la esfera de lo económico y de las relaciones sociales que son ajenas al hogar. Es decir, las mujeres van a poder participar en el desarrollo sólo en la medida en que se incorporen a la esfera pública (Benería, Sen, 1981). Pero de poco sirve poner el énfasis en las contradicciones de clase y en la necesidad de incrementar la participación de la mujer en el área no doméstica de la producción, sin fundamentar el análisis en las relaciones de patriarcado que subyacen con independencia del modo de producción capitalista.

Puesto que el enfoque MED define los problemas de las mujeres en términos de las necesidades básicas de las familias y no tanto en base a la subordinación que ellas experimentan en la esfera reproductiva, los programas de desarrollo que se derivan de este enfoque tienden a buscar el productivismo de las mujeres pobres en el ámbito doméstico y en los oficios tradicionalmente femeninos - como la costura- Este tipo de programas sirven para remarcar el carácter secundario de la mujer en la esfera productiva, así como para estimular el trabajo gratuito de las mujeres y reforzar su rol en la esfera reproductiva. Ante este panorama, es improbable que se asista a cualquier potencial de cambio de las relaciones de poder entre hombres y mujeres (Afshar, 1999; Massolo, 1999). El trabajo total de las mujeres se incrementa, sin lograr por ello un mayor acceso al poder económico y sin erigirse como agentes capaces de diseñar el tipo de desarrollo que necesitan. Por lo tanto, puede afirmarse que el enfoque MED tiende a que las mujeres trabajen para el desarrollo, en vez de que el desarrollo trabaje para ellas ${ }^{10}$ (Zabala, 1999).

La principal limitación que se atribuye a las distintas versiones del enfoque MED es la no articulación de una crítica profunda al sistema de producción. Desde un punto de vista teórico, dichas teorías no se plantean cuál es la relación entre la división sexual del trabajo y los patrones de segregación sexual en el mercado laboral. La experiencia de las sociedades occidentales demuestra

10. En definitiva, estos planteamientos sintonizan perfectamente con los objetivos de las políticas de ajuste estructural, cuyas premisas se traducen en la reducción del gasto público a costa de utilizar el trabajo gratuito de las mujeres como recurso infinitamente elástico para seguir satisfaciendo las necesidades familiares. 
que la elevación de los niveles de escolaridad, la disponibilidad de tecnologías reproductivas y la incorporación de las mujeres al trabajo asalariado no han eliminado ni la segregación ocupacional ni las diferencias salariales entre hombres y mujeres, ni tampoco el reparto desigual del trabajo reproductivo. A pesar de que la mujer con un empleo remunerado efectivamente cuenta con mayores cotas de derechos y participación en la esfera pública, se puede constatar que el acceso al empleo y las condiciones laborales se reparten de manera desigual entre los hombres y las mujeres, toda vez que las estrategias de flexibilización y desregulación del mercado de trabajo son un fenómeno claramente sexuado (Meulders, 2000; Walby, 2000). El tipo de relación que mantiene la mujer con el trabajo remunerado (mayor incidencia del desempleo, de los empleos a tiempo parcial, eventuales y mal remunerados, trayectorias laborales discontinuas) la sigue exponiendo en mayor medida a la pobreza y genera derechos desiguales en el acceso a las prestaciones de la seguridad social; unas prestaciones basadas en las formas masculinas de participación en el mercado laboral $^{11}$. La realidad muestra que la mujer concurre a los empleos menos cualificados, peor pagados y menos valorados, con una escasa presencia en los puestos de responsabilidad y en política. Las mujeres están siendo, en la actualidad, "testigos privilegiados» de la degradación de las condiciones de empleo y de trabajo; lo que evidencia que la desigualdad varón/mujer no desaparece, sino que se desplaza hacia «nuevas fronteras» (Maruani, 2000).

A pesar de que desde la Primera Conferencia Mundial de México ${ }^{12}$, celebrada en 1975, existe una creciente preocupación — tanto desde las instituciones internacionales como desde las agencias gubernamentales - por los problemas con los que debe enfrentarse la mujer del Tercer Mundo en su vida social y económica, las distintas estrategias adoptadas son profundamente limitadas. Es cierto que se empieza a reconocer la contribución de la mujer en la satisfacción de las necesidades básicas a través del trabajo doméstico y que se reivindica la necesidad de que los distintos programas de desarrollo contribuyan a aligerar esta carga, con el fin de avanzar en el logro de la independencia económica. En la misma línea, las Estrategias de Nairobi ${ }^{13}$, aprobadas en 1987, postulan a favor de dedicar esfuerzos para aumentar el acceso de la mujer a las

11. La naturaleza de la pobreza tiene una clara base de género. El incremento del número de divorcios y separaciones deja a las mujeres en una situación económica desfavorecida, ante su mayor dificultad a la hora de encontrar un empleo y un salario suficiente (González, 2001).

12. El papel de las Naciones Unidas ha sido decisivo en el proceso de avance de la igualdad entre hombres y mujeres. Además de contar con instrumentos internacionales para la defensa de los derechos de la mujer, ha potenciado la realización, hasta ahora, de cuatro conferencias mundiales sobre la mujer: la primera de ellas se celebró en México, en 1975; la segunda, en Copenhague, en 1980; la tercera, en Nairobi, en 1985, y la cuarta, en Pekín, en 1995.

13. Texto aprobado en la Conferencia Mundial para el Examen y la Evaluación de los Logros del Decenio de las Naciones Unidas para la Mujer: Igualdad, Desarrollo y Paz (III Conferencia Mundial sobre las Mujeres), celebrada en Nairobi (Kenya), del 15 al 26 de julio de 1985 (IMU, 1987). 
actividades que generan ingresos y a las fuentes de crédito, «puesto que la independencia económica es un requisito previo para la autosuficiencia de la mujer» (IMU, 1987: 66). Si bien esta postura es valiosa, en tanto que reconoce el trabajo no remunerado de la mujer e, implícitamente, la interrelación entre la esfera reproductiva y la productiva, no se cuestionan las responsabilidades tradicionales de la mujer y, por lo tanto, tampoco las relaciones patriarcales o la división sexual del trabajo.

Una vez más, la experiencia de las mujeres en los países occidentales nos sirve de ejemplo. Su participación masiva en el mercado de trabajo en los últimos años sin duda les ha supuesto el logro de niveles de igualdad con respecto a los varones sin precedentes; sin embargo, no las exime de tener que seguir realizando la mayor parte del trabajo reproductivo, a menos que opten por seguir miméticamente el modelo de empleo masculino y se «liberen» de las responsabilidades familiares renunciando a ellas ${ }^{14}$. Lamentablemente, la asunción de nuevos roles laborales no supone una ruptura con los viejos roles domésticos. A pesar de que las presiones sobre el hombre para que comparta las responsabilidades reproductivas son cada vez más acusadas, los datos estadísticos siguen reflejando que, por ahora, la incorporación de la mujer al mercado de trabajo no va acompañada de una distribución igualitaria del trabajo doméstico, y los sistemas simbólicos de representación masculinos apenas se han alterado (IMU, 1997). En este sentido, sólo la mujer de clase media y alta podrá «ocultar» parte de la subordinación mediante la mercantilización del trabajo doméstico. Para la mujer de clase baja, en cambio, la incorporación a la esfera productiva supone añadir nuevas jornadas de trabajo. Por consiguiente, de poco va a servir concentrarse exclusivamente en los efectos de los programas de desarrollo sobre la mujer, si no se parte de las relaciones de poder subyacentes que definen la condición de la mujer y del hombre en la sociedad (PNUD, 1995: 116; Zabala, 1999). Tal como señalan Benería y Sen, «para la mujer pobre, el empleo remunerado no disminuye en ninguna forma los efectos inherentes de su género y de su clase. Para ellas, la satisfacción de sus necesidades básicas en condiciones de igualdad con el hombre requiere que los cambios sean más profundos» (1983: 107).

A lo largo de las décadas de los ochenta y noventa se introducen propuestas teóricas más elaboradas, que recogen el impacto diferencial de los programas de desarrollo sobre los hombres y las mujeres, debido a la existencia de roles distintos entre los géneros. En este sentido, si bien se constata que los programas de desarrollo inciden positivamente sobre las necesidades de las mujeres (vivienda, salud, educación, alimentación, etc.), sigue sin avanzarse en sus intereses a largo plazo (división sexual del trabajo, acceso a la tierra y al crédito, igualdad política, superación de la violencia de género, decisión libre de la maternidad, alivio de las cargas domésticas, etc.), puesto que éstos tienen que

14. Pero la «masculinización» del estilo de vida sólo es posible en el caso de la maternidad, puesto que las mujeres que hoy trabajan en el mercado laboral deben hacer frente a la «dependencia» de sus progenitores y no pueden eludirla. 
ver con la posición de las mujeres en las relaciones de género y con el modelo de desarrollo (Luna, 1999: 70). Para estas autoras, la tan alardeada «integración en el desarrollo» que propugna el enfoque MED se ha convertido en una «integración en la explotación»; por lo que ya no les preocupa tanto la exclusión de las mujeres del proceso de desarrollo, como las relaciones desiguales de poder —clase y género- que frenan un desarrollo igualitario (Afshar, 1999: 75) ${ }^{15}$.

En este contexto aparece el enfoque GED, Género en el Desarrollo, que incorpora nuevos elementos para explicar la subordinación femenina, a través del empowerment o acceso paulatino de las mujeres al control de los recursos materiales, intelectuales y de ideología; se trata de que ellas mismas, en calidad de agentes directamente afectados, puedan participar en el diseño de las políticas y en los beneficios del desarrollo (Fuller, 1999; Luna, 1999; Massolo, 1999; Afshar, 1999). La propuesta GED propugna la toma de conciencia por parte de las mujeres de su subordinación; la organización autónoma para decidir sobre sus vidas y sobre el desarrollo que desean, así como la movilización para la identificación de sus intereses prácticos y estratégicos (Luna, 1999). El enfoque GED cambia el foco de «mujer» a "género»; de manera que en lugar de visualizar a las mujeres como un grupo homogéneo, en base a sus diferencias biológicas con los hombres, se enfatiza la construcción social del género, en interrelación con otras categorías sociales como la clase social y la etnia o raza (Massolo, 1999). A diferencia del enfoque MED, puesto que el género es un concepto relacional, la responsabilidad del cambio no sólo concierne a las mujeres, sino que se desplaza hacia hombres y mujeres en todos los niveles del proceso de desarrollo (Massolo, 1999; Luna, 1999).

Los objetivos de este enfoque alternativo son desafiar la ideología patriarcal; transformar las instituciones que refuerzan y perpetúan la discriminación social y las desigualdades de género, así como permitir a las mujeres el acceso a los recursos materiales y a la información (Afshar, 1999). Este novedoso enfoque constituye el reto actual de las políticas de desarrollo, en aras a lograr, por primera vez, un cambio real en las relaciones sociales y de género (Ajamil, 1999) ${ }^{16}$. Las estrategias de empowerment que plantea el GED están teniendo un fuerte eco dentro del enfoque de desarrollo alternativo impulsado por el Programa de Naciones Unidas para el Desarrollo (PNUD) a lo largo de la década de los noventa. Su principal objetivo es aumentar las oportunidades y capacidades de los individuos como fin último del desarrollo y transformar las relaciones de género, de modo que sean más equitativas y justas para las mujeres (PNUD, 1995; Zabala, 1999).

15. El debate entre igualdad y desarrollo está muy bien documentado en el informe Desarrollo, crisis y enfoques alternativos. Perspectivas de la mujer en el Tercer Mundo, redactado por las mujeres del Sur DAWN-MUDAR (red de activistas e investigadoras del Tercer Mundo) y presentado en el Foro Alternativo de la $3^{\text {a }}$ Conferencia Mundial de Nairobi (Afshar, 1999: 75).

16. Este enfoque se entrevé claramente en los documentos adoptados durante la IV Conferencia Mundial sobre las Mujeres, celebrada en Beijing (China) en 1995, con la finalidad fundamental de examinar y evaluar el avance de las mujeres en relación con los objetivos que se habían planteado en las Estrategias de Nairobi (IMU, 1997). 


\section{La participación de las mujeres en el desarrollo}

Ciertamente, cualquier estudio sobre desarrollo no puede minusvalorar la importante contribución de las mujeres desde su participación en la esfera reproductiva. A pesar de llegar a la conclusión de que a todas las mujeres y en todas las sociedades se les destina el trabajo reproductivo - por lo que el concepto de la división sexual del trabajo tiene validez universal- , no debe olvidarse que el significado y el contenido de tal asignación son muy distintos según se trate de contextos urbanos e industrializados o de áreas rurales agrícolas. El trabajo reproductivo es una construcción social que varía a lo largo de la historia y de las sociedades, un complejo entramado de prácticas simbólicas y materiales que no puede separarse de las creencias culturales y de los constreñimientos estructurales (Coltrane, Galt, 2000). Ciertamente, en todos los casos se trata de trabajo no remunerado y que implica manejar muchas actividades a la vez; pero el marco social en el que se llevan a cabo estas tareas es muy versátil y existen diferencias en torno al contenido, a la cantidad y a la intensidad de las tareas.

En los países industrializados, las mujeres disponen de electrodomésticos que hacen cada vez más llevaderas las labores más pesadas y disminuyen el tiempo preciso para su realización ${ }^{17}$; mientras que en los países en desarrollo, el trabajo reproductivo tiene lugar bajo unas condiciones materiales de gran dureza, debido al elevado número de hijos y a la falta de servicios, equipamientos e infraestructuras ${ }^{18}$. En estos países, es usual que las mujeres acarreen agua a lo largo de grandes distancias, recojan leña, limpien y trituren los cereales; por lo que tanto el volumen de las tareas reproductivas como su intensidad es mucho mayor ${ }^{19}$. Las políticas de ajuste estructural o el empeoramiento de las condiciones ambientales contribuyen directamente a intensificar el

17. Es cierto que la difusión en masa de los aparatos electrodomésticos, así como también el cambio en los hábitos alimentarios, facilita en gran medida las labores domésticas propiamente dichas (Croff, 1996). Sin embargo, la reducción de algunas actividades domésticas ha sido acompañada de la creciente expansión de nuevas tareas familiares, como por ejemplo las de mediación, la gestión afectiva, la planificación, la organización del tiempo de ocio de la familia. Por otro lado, las tareas directamente vinculadas al cuidado de las personas siguen intactas y el proceso de envejecimiento de la población aumenta su volumen.

18. De hecho, según Fernández Enguita (1989), los avances tecnológicos, así como el desarrollo de la oferta del mercado y los servicios públicos no parecen haber sido capaces de reducir globalmente la jornada laboral del ama de casa en los países industrializados. Este es el caso, por ejemplo, del cuidado de los niños pequeños, que en el contexto de la familia extensa rural estaba a cargo de varias personas, mientras que en la familia nuclear urbana, con las generaciones separadas físicamente, corre a cargo prácticamente en exclusiva de los padres. Por otra parte, el concepto de limpieza que se aplica hoy en día no tiene nada que ver con el de hace cincuenta años.

19. La situación más precaria se da en las zonas rurales y, en especial en el continente africano, donde se estima que la distancia media a las fuentes es de cinco kilómetros y que el transporte del agua consume aproximadamente el $25 \%$ de la ingesta calórica total de las mujeres (Momsen, 1991). 
trabajo reproductivo ${ }^{20}$, puesto que alteran la relación existente entre la esfera productiva y la reproductiva en perjuicio de las mujeres. Los paquetes de medidas estabilizadoras que se aplican en muchos países en desarrollo a partir de la década de los ochenta, conllevan severos recortes en los gastos sociales y el aumento de los precios de los productos básicos; lo que se traduce en un cambio de las estrategias familiares y en el aumento del trabajo reproductivo de las mujeres (más necesidad de aumentar la autoproducción en el hogar —cocinar, tejer-, cambios en los hábitos de compra, asistencia sanitaria básica, etc.) $)^{21}$.

Pero, lejos de equiparar el papel de la mujer en el desarrollo con su presencia en la esfera reproductiva, no debe olvidarse que también está presente en la esfera productiva en las sociedades periféricas. El tipo de participación de la mujer en la esfera productiva difiere en las distintas sociedades. Aún así, en todas partes dicha participación viene determinada por el rol atribuido a la mujer en la esfera reproductiva; és decir, la concreción de la experiencia de las mujeres en la esfera productiva está muy arraigada en la contradicción que resulta de la división sexual del trabajo (Fernández-Kelly, 1991). Pero las experiencias socioeconómicas femeninas también dependen de otros factores, tales como otras características culturales - estructura del hogar, religión, etc.—, o la naturaleza del proceso productivo — régimen de propiedad de la tierra en las sociedades agrarias, las estrategias de flexibilización de los mercados de trabajo en las sociedades industriales, la introducción de nuevas tecnologías-, sin olvidar los condicionantes socio-políticos (Benería, 1981; Benería, Sen, 1983; Brydon, Chant, 1989; Moore, 1999).

Por lo tanto, en las actividades no domésticas la división sexual del trabajo es mucho más compleja y no puede explicarse únicamente a partir de las «necesidades del capital» o de las circunstancias económicas, aunque éstas sean, sin duda, muy importantes. Los análisis realizados desde una óptica occidental tienden a extrapolar la uniformización cultural que se da en estas sociedades y a otorgar un excesivo protagonismo a los agentes económicos, lo que impide ver que los roles de género tienen su propia dinámica. Los estereotipos relativos a los trabajos remunerados considerados femeninos o masculinos no son universales, sino el fruto de la conjunción entre las exigencias del sistema

20. A consecuencia de las industrias de tala de árboles y de la cría de ganado se produce la deforestación y la erosión de los suelos, lo que comporta la pérdida de leña y el agotamiento de los recursos de agua. Eso aumenta el tiempo y la energía que las mujeres deben dedicar a recoger agua y leña (PNUD, 1995).

21. Las políticas de austeridad han causado serios reveses a la educación y a la sanidad de las mujeres. La presión del deterioro de la calidad de vida tiene como resultado que muchas madres recurran a sus hijas — en mayor medida que a sus hijos - para que ayuden en las tareas domésticas o a generar ingresos, lo que significa apartarlas de la escuela. La reducción de los programas de educación sanitaria comporta una mayor incidencia de la desnutrición y facilita la propagación de enfermedades, sobre todo las de transmisión sexual como el VIH (Bifani, 1999). 
productivo y la oferta del sistema reproductivo ${ }^{22}$. Tal como sostiene Boserup (1970), el distinto rol que asume la mujer en la esfera productiva en todo el mundo es la variable clave a la hora de explicar las diferencias en su condición social. Sin embargo, sí se detectan una serie de constantes en todas las sociedades, tales como el hecho de que las mujeres sean principalmente segregadas en aquellos espacios de la estructura ocupacional donde el empleo se ve como una extensión de sus responsabilidades domésticas; que se les asignen los empleos de baja productividad y reducidos salarios y que se defina el sueldo femenino como suplemento del ingreso del hombre. Es así como el trabajo remunerado femenino se considera inferior al masculino, no tanto por la tarea en sí misma, sino porque las trabajadoras arrastran su inferioridad de estatus al puesto de trabajo (Moore, 1999).

En los países periféricos, tanto la globalización de la economía como los períodos de crisis y el deterioro de las condiciones económicas, obligan a todos los miembros de la familia a buscar nuevas rentas con las que atender las necesidades familiares; por lo que se está produciendo un rápido acceso de las mujeres a los trabajos remunerados, en condiciones de precariedad extrema y marcado por la elevada carga de trabajo reproductivo que deben soportar. A pesar de que, tal como ya se ha apuntado anteriormente, la naturaleza exacta de este trabajo remunerado varía de una cultura a otra, es cada vez más habitual encontrar a la mujer trabajando en las explotaciones agrarias, en tareas artesanales, en la construcción, en los servicios - sobre todo en el servicio doméstico y en los servicios personales - , en sectores marginales o ilegales como la prostitución; sin olvidar las pequeñas industrias tradicionales y las industrias modernas vinculadas al capital internacional, que encuentran en la mujer campesina la fuente más barata de fuerza de trabajo.

Aproximadamente la mitad de las mujeres del mundo viven y trabajan en tierras de cultivo en países en desarrollo, llegando a producir entre el $40 \%$ y el 80\% del total de la producción agrícola ${ }^{23}$ (Moore, 1999: 60). Puesto que los avances tecnológicos se suelen enunciar en masculino, la mayoría de las actividades agrarias que realizan las mujeres no se han mecanizado - a diferencia de las masculinas-, por lo que su carga de trabajo se incrementa (Pearson, 1999). Sin embargo, no debe asociarse directamente el hombre con la agricultura moderna y la mujer con la agricultura de subsistencia, destinada al consumo doméstico y con tecnologías básicas y tradicionales. La realidad es mucho más compleja. Los estudios de Boserup (1970) ponen de manifiesto que existe una clara relación entre las estructuras agrarias y los roles de la mujer en la esfera productiva, a pesar de que en estos casos resulta difícil separar las

22. En los países árabes, por ejemplo, la mujer no se emplea en el servicio doméstico o en la hostelería, puesto que se trata de actividades consideradas inadecuadas para ella, simplemente porque entrañan excesivo contacto con personas de sexo masculino (Moore, 1999).

23. Esta realidad contrasta con las bajas tasas de actividad femenina que tienen algunos de estos países (sobre todo los países árabes), lo que pone de manifiesto que el reconocimiento real de la participación de la mujer en la actividad productiva es muy limitado si se hace uso de este tipo de indicadores (López, 1997). 
actividades domésticas (esfera reproductiva) de las productivas ${ }^{24}$. La disponibilidad de tierras colectivas y la baja densidad de población en África sirven para explicar el destacado papel que desempeñan las mujeres africanas en la producción agrícola, tanto de subsistencia como comercial ${ }^{25}$; mientras que la abundancia de mano de obra masculina en los países asiáticos o el predominio de latifundios en Latinoamérica ha relegado a la mujer al hogar o al cultivo de una agricultura de subsistencia no orientada hacia el mercado.

De hecho, en América Latina la modernización de la agricultura ha reducido las alternativas laborales de las mujeres, que deben elegir entre proletarizarse en la industria o bien emigrar hacia las ciudades para emplearse como trabajadoras domésticas. En cambio, los cultivos intensivos de exportación (recolección, selección y empaquetado de frutas y hortalizas y flores) sí optan por reclutar a mujeres como asalariadas — preferentemente jóvenes y sin hijos-, puesto que ello permite a la agroindustria abastecerse de una fuerza de trabajo estacional, usualmente a destajo, con ritmos de trabajo dependientes de las exigencias de la cosecha y con salarios más bajos que los que percibirían los hombres ${ }^{26}$. Esta realidad contradice, sin lugar a dudas, el tópico de la escasa participación de las mujeres latinoamericanas en el sector agrario ${ }^{27}$ e ilustra perfectamente de qué manera el capital utiliza en beneficio propio las desigualdades de género (Sabaté y otros, 1995).

En lo que se refiere al trabajo de las mujeres en el sector servicios, éste constituye un importante sector de empleo, debido a los procesos de urbanización que están teniendo lugar en las sociedades menos desarrolladas ${ }^{28}$. Las mujeres desempeñan mayormente actividades en torno principalmente al comercio a pequeña escala y al servicio doméstico. Se trata de ocupaciones consideradas no especializadas y poco o nada reglamentadas, por lo que en ellas predomina la economía informal y la inestabilidad. También es cada vez más frecuente la presencia de mujeres en sectores marginales o ilegales como la prostitución ${ }^{29}$.

24. La división entre producción y espacio doméstico o entre esfera productiva y reproductiva no puede ser generalizada y no constituye un marco válido para el análisis de género en todas las culturas, tal como se señala desde la antropología. La separación de la vida social en una esfera "doméstica» y una "pública» no tiene razón de ser en comunidades pequenas, donde la producción y la administración de la unidad doméstica forman parte, simultáneamente, de la vida pública, económica y política (Moore 1999).

25. Según datos de Naciones Unidas para 1995, en África las mujeres representan el $80 \%$ de los productores de alimentos (PNUD, 1995: 46).

26. Véase al respecto un artículo de Bifani (1997) y un interesante estudio de Barrientos (1999) sobre las mujeres en las agroindustrias chilenas.

27. Si bien la obra de Boserup (1970) fue pionera en su momento y sigue siendo de gran utilidad para comprender la situación de las mujeres en el Tercer Mundo, sus análisis no sobrepasan los años sesenta, por lo que deben ser tenidas en cuenta sus limitaciones cronológicas e ideológicas.

28. El sector servicios presenta una importante variabilidad regional; mientras en América Latina y Caribe ocupa al $72 \%$ de las mujeres económicamente activas, en Asia comprende un 40\% del empleo femenino y en África apenas alcanza el 20\% (Sabaté y otros 1995: 109).

29. Muchos campesinos pobres, que se han quedado sin recursos con el desarrollo de la agricultura para la exportación, envían a sus hijas a las ciudades para que se prostituyan. Se estima que, en Brasil, 4,5 millones de chicas menores de veinte años trabajan en la prostitución y que 
El sector formal, por su parte, se limita a los servicios administrativos y sociales (administración pública, trabajos de oficina, enseñanza, enfermería, etc.), integrados básicamente por mujeres con niveles educativos medio-altos. Estas ocupaciones en el sector formal están siendo cada vez más flexibilizadas, con el fin de aumentar la «eficiencia» en el sector público, lo que se consigue a costa del deterioro de las condiciones de trabajo de las mujeres. La reducción del empleo en el sector público también ha tenido como resultado la incorporación de muchas mujeres en el sector informal como estrategia de supervivencia, a la vez que se convierten en potenciales emigrantes ${ }^{30}$.

Por otra parte, diversos estudios han documentado el papel de la mujer en los procesos de industrialización de muchos países y su participación en la producción para el mercado global ${ }^{31}$. De la mano de la incorporación de las mujeres a la fuerza de trabajo industrial de los países periféricos, se rompe la extendida creencia de que su papel en el desarrollo se reduce a los trabajos de subsistencia y a las pequeñas actividades comerciales; de ese modo, el género se convierte en una dimensión importante dentro de la investigación sobre desarrollo. Tal como reconoce Fernández-Kelly (1991), la incorporación de las mujeres a la fuerza de trabajo de las plantas maquiladoras ${ }^{32}$, tanto en Asia como en América Latina y en otras partes del mundo, permite una mejor comprensión del papel de las mujeres en el desarrollo económico, como parte esencial del proceso de internacionalización económica. Sin lugar a dudas, las maquiladoras ilustran los efectos de una nueva división internacional del trabajo estratificada de acuerdo con la nacionalidad, la clase social y el género. Pero qué duda cabe que la incorporación de grandes contingentes femeninos para reducir los costos de producción en el contexto de la nueva economía transnacional tiene claros precedentes en otros momentos históricos, tales como la Revolución Industrial o la producción de bienes de capital en Estados Unidos durante la Segunda Guerra Mundial. Ello demuestra que ante las necesidades del capitalismo se desarrollan estrategias parecidas (a pesar de las diferencias regionales en la construcción social del género), incluso en países o en contextos históricos en los que la participación de la mujer en trabajos remunerados no es socialmente aceptable 33 (Benería, 1998, 1999).

el 50\% de los chicos y chicas de Manila ejercen la prostitución infantil. En Tailandia, donde el turismo sexual es una de las principales fuentes de riqueza del país, casi un millón de mujeres son prostitutas (Morokvasic, 1993).

30. Véanse al respecto los estudios de Benería, Sen (1983); Sabaté y otros (1995); PNUD (1995); López (1997); Afshar (1999); Bifani (1999); De la Cruz (1999); Bakker (1999); Moore (1999); Pearson (1999); Zabala (1999); Peña (2001).

31. Lim (1983); Sassen (1984); Benería (1991); FNUAP (1993); Sklair (1995); Luna (1999); Moore (1999).

32. La maquila consiste en la actividad de montaje, a partir de piezas procedentes del exterior, de productos elaborados acabados que se destinan a la exportación. Esta actividad se realiza en las zonas francas de los países periféricos (Vidal Villa, 1995).

33. En países como Bangladesh, por ejemplo, donde las barreras y los prejuicios con respecto al trabajo remunerado de la mujer son bastante rígidos, la incorporación de la mujer al mercado de trabajo ha ido acompañada de una campaña ideológica que lo justifica (Benería, 1991). 
Según Sassen (1984), en los lugares donde predomina la producción industrial para la exportación, las mujeres que abandonan el campo se dirigen en menor proporción al sector servicios ${ }^{34}$. Existe una relación sistémica entre la globalización del capitalismo y la feminización de la fuerza de trabajo. Los procesos de "deslocalización» industrial crean empleo femenino mal remunerado y éste es potenciado y apoyado desde las propias políticas estatales, con la finalidad de atraer la inversión extranjera. La confluencia entre la demanda global de mujeres trabajadoras en las industrias periféricas y el declive de las oportunidades económicas de las mujeres en las zonas rurales, provoca intensos flujos migratorios rurales-urbanos de mujeres jóvenes que buscan trabajo en la industria y que constituyen un "nuevo proletariado» a nivel mundial (Willis, Yeoh, 1999; Moore, 1999). Éste es el caso de las zonas francas ${ }^{35}$ — también llamadas «zonas de procesamiento para la exportación» que se han creado en países del Tercer Mundo y que atraen a muchas trabajadoras no cualificadas a industrias como la electrónica, la confección de ropa, los textiles y la fabricación de juguetes y de calzado (Lim, 1983; Sassen, 1984; FNUAP, 1993). La fuerte presencia de mujeres jóvenes en las industrias maquileras (85\%), en la frontera entre México y EUA, o el 84\% de mujeres en las zonas francas industriales de la República Dominicana, son un claro ejemplo (Bifani, 1997). Sin embargo, no debe olvidarse que los índices de participación femenina no pueden generalizarse, puesto que los factores que los determinan —al igual que ocurre con la presencia de la mujer en la esfera productiva, en general- son complejos y dinámicos, fruto de la interacción entre los condicionantes del sistema productivo y las relaciones de género ${ }^{36}$. De ese modo, mientras que la incorporación de las mujeres en la industria es bastante notoria en los países de reciente industrialización de Asia, África del Norte, Caribe y América Latina, apenas existe en el África subsahariana, Oriente Medio o Asia Meridional (Sabaté y otros, 1995: 260).

Este «nuevo» proletariado femenino constituye una fuerza de trabajo especialmente flexible, disciplinada y barata. Los salarios son muy bajos y la retribución suele hacerse a destajo, en función de la producción. Las condiciones laborales de estas trabajadoras son sumamente desfavorables y precarias y, generalmente, carecen de la posibilidad de promoción, así como de organizarse a nivel

34. Esta idea contradice el patrón migratorio que se desprende de la literatura sobre migración femenina de los años cincuenta, sesenta e incluso setenta — personificada en los trabajos de Boserup (1970)_, según la cual la mayoría de mujeres inmigrantes en las ciudades se emplean en el servicio doméstico y el sector informal.

35. Zonas de reducido tamaño dentro de un país, cuyo propósito es atraer empresas industriales orientadas a la exportación y que ofrecen unas condiciones muy atractivas para la inversión. Además, tanto la importación como la exportación desde estas zonas está libre de impuestos.

36. Como principales condicionantes cabría destacar: la estructura de la economía, el nivel de industrialización, las oportunidades educativas para las mujeres, los valores culturales relativos a los roles femeninos, la estructura demográfica, la edad legal para contraer matrimonio y la posición jurídica de la mujer (Moore, 1999: 124). 
sindical ${ }^{37}$ (Benería, 1991; Moore, 1999). Es común que o bien no existan leyes laborales que las protejan, o que éstas no se cumplan, de manera que se enfrentan a prolongadas horas de trabajo y a deficientes condiciones laborales y de vivienda, con importantes riesgos para su salud. Puesto que se trata de actividades sumamente repetitivas, estas empresas optan por la rotación y la sustitución de las trabajadoras, lo que aumenta todavía más su desprotección. La mano de obra femenina resulta más barata que la masculina, aunque realicen la misma actividad, puesto que culturalmente se asume que el salario del hombre debe servir para mantener a la familia, a diferencia del de la mujer. La transnacionalización de la producción se aprovecha de la fragmentación por sexos de la fuerza laboral dentro de un país, lo que posibilita a las multinacionales operar con un coste mucho más reducido que el que tendrían que asumir en los países del centro.

Pero, además, según Benería (1991: 30), la fuerza de trabajo femenina ofrece otro tipo de ventajas en función de una serie de cualidades o características de género que se le atribuyen de manera estereotipada y que determinan su ubicación en la producción en un orden jerárquico de subordinación: su mayor sumisión y sometimiento a la disciplina del trabajo; su menor participación en actividades sindicales debido a sus obligaciones domésticas; su mayor delicadeza, destreza manual ${ }^{38}$ y disciplina, especialmente para actividades que requieran de precisión, cuidado y paciencia; su mayor predisposición a aceptar la flexibilidad laboral y los bajos salarios, etc. (Benería, 1991; Sklair, 1995; Luna, 1999; Moore, 1999). Estas características son vistas como inherentes a la condición femenina y no como resultado de un proceso de socialización específico para las mujeres.

Como consecuencia de lo apuntado, las empresas multinacionales, en general, prefieren a mujeres jóvenes — menores de veinticinco años—, solteras y procedentes del ámbito rural, sin cargas familiares que reduzcan su productividad o que las ausente del lugar de trabajo. Además, su extrema juventud y su procedencia rural muchas veces contribuye a que sean mujeres más dóciles, que sustituyen la autoridad paterna por la del empresario ${ }^{39}$ (Safa, 1984). Cuando se trata de mujeres con cargas familiares, las empresas suelen ofrecerles trabajo informal y a domicilio (putting-out system). Las trabajadoras industriales a domicilio realizan en sus casas las fases peor pagadas de la producción industrial, totalmente aisladas; sin duda, constituyen el último eslabón en los

37. Sólo a través de episodios dramáticos se dan a conocer estas condiciones de sobreexplotación, como el terremoto ocurrido en Ciudad de México en el año 1985, en el que perecieron unas ocho mil costureras que trabajaban en talleres insalubres. Además, otras cuarenta mil mujeres perdieron su puesto de trabajo, ya que los empresarios optaron por trasladarse a otro país (Sabaté y otros 1995: 268).

38. Muchas de las tareas que desempeñan requieren «dedos de hada», una gran concentración y una atención al detalle (Bifani, 1997).

39. En el caso de la República Dominicana, se constata una preferencia por mujeres jóvenes con cargas familiares, en base a la creencia de que su necesidad de trabajar las convierte en mejores trabajadoras (Martínez Veiga, 1997). 
procesos de «deslocalización» industrial. Qué duda cabe que tanto los bajos salarios como la flexibilidad de las mujeres en horario, tiempo y entrada y salida del mercado laboral encajan perfectamente con las necesidades de la nueva economía ${ }^{40}$ (Castells, 1998: 195).

En definitiva, la «feminización» de la fuerza de trabajo en las industrias para la exportación demuestra que la mujer no queda al margen de la esfera productiva, sino que, justamente, la penetración del capitalismo la convierte, en muchos casos, en fuerza de trabajo "preferente». De estas constataciones se desprende que las mujeres de los países periféricos son uno de los colectivos más explotados a nivel mundial, puesto que están sujetas tanto a la explotación imperialista como a la patriarcal. Las empresas multinacionales se aprovechan de la inferior posición de la mujer en el mercado de trabajo y las emplean por inferiores salarios y bajo peores condiciones laborales que las que existen para los hombres en el mismo país, o para las mujeres efectuando las mismas tareas en los países desarrollados, lo que les permite vender sus productos a precios competitivos en los países del centro ${ }^{41}$.

Llegados a este punto, es necesario preguntarse en qué medida este «nuevo» empleo en las industrias para la exportación representa una fuente de emancipación y de autonomía para las mujeres - la mayoría de origen rural-, frente a las distintas instituciones patriarcales propias de cada país, o, por el contrario, una fuente de explotación y de discriminación. Los diferentes estudios que se han llevado a cabo demuestran que ambos efectos no son excluyentes, sino que se dan de manera simultánea (Tienda, Booth, 1991; Phizacklea, 1999). A tenor de los datos de Lim (1983), las condiciones de trabajo y los salarios en las multinacionales son generalmente mejores que en los empleos alternativos para las mujeres (industrias locales, economía informal, servicio doméstico, prostitución), lo que les permite responder al aumento incesante del coste de la vida ${ }^{42}$. Por otro lado, el trabajo remunerado, a pesar de los bajos salarios, les da la oportunidad de acceder a la sociedad de consumo, abandonar el hogar y ejercer su independencia personal, ya que les otorga una cierta autonomía económica y un cierto grado de emancipación social; aunque sigan todavía subordinadas al núcleo familiar ${ }^{43}$. Sin embargo, los cambios en las relaciones de género dependen especialmente de la edad o la etapa vital en la que las mujeres se incorporan a la industria. En el caso de los países asiáticos, las transformaciones en las relaciones de género son insignificantes, puesto que

40. Existe un claro paralelismo entre las condiciones laborales que padecen las mujeres de la periferia y las que tuvieron que soportar las mujeres europeas en las fábricas durante la Revolución Industrial, como por ejemplo las mujeres trabajadoras en las hilaturas de Cataluña.

41. Como señala Afshar: «Era obvio que, si las industrias de electrónica empezaban a emplear a mujeres de color en Gran Bretaña, esto significaba que la industria estaba lista para «marcharse» al Tercer Mundo, donde los salarios son incluso más bajos» (1999: 57).

42 Por lo tanto, según la autora, aunque en términos relativos es mayor la explotación en las multinacionales, no lo es en términos absolutos.

43. Sin embargo, las duras condiciones laborales a las que se enfrentan convierten estas experiencias en «liberadoras», en el sentido más básico del término (Moller, 1996: 197). 
las empresas contratan solamente a jóvenes solteras y éstas suelen dejar de trabajar al contraer matrimonio, retomando así los roles tradicionales de esposas y madres. Sin embargo, en los países latinoamericanos, donde es frecuente que las mujeres con hijos a cargo sigan trabajando - y, además, existe un elevado desempleo masculino-, las mujeres se convierten en el principal sostén económico de la familia y ello sí conlleva variaciones importantes en las relaciones de género ${ }^{44}$.

Otro efecto a tener en cuenta es la introducción de pautas de consumo nuevas a las que antes no tenían acceso (Benería, 1991). Autoras como Sassen (1993), Nash y Fernández-Kelly (1983), argumentan que la preferencia de mujeres por parte de las multinacionales genera disrupciones en las estructuras familiares tradicionales. En muchas sociedades, el hecho de haber trabajado en la industria conlleva un estigma social, por lo que estas mujeres difícilmente van a ser aceptadas en sus comunidades de origen y pueden incluso perder toda posibilidad de contraer matrimonio (Bifani, 1997). Una vez estas mujeres se ocupan en las fábricas, la precariedad y las duras condiciones de trabajo a las que deben enfrentarse, así como la occidentalización de los estilos de vida que conlleva, las convierte en firmes candidatas a protagonizar las migraciones internacionales (Sassen, 1984, 1998). Por lo tanto, puede afirmarse que las migraciones internas y la asalarización de las mujeres en las industrias de los países de origen están directamente vinculadas al empleo de las mujeres inmigrantes en los servicios mal pagados de los países centrales ${ }^{45}$.

En cualquier caso, la razón principal de estas mujeres para incorporarse al trabajo remunerado es la necesidad de percibir recursos monetarios y, por el momento, no parece que las condiciones en las que se da permitan modificar sustancialmente las bases del patriarcado - de las que el propio capitalismo se sirve- o contribuyan a valorar el trabajo realizado por las mujeres. Al margen de los «beneficios» mencionados en términos de logro de autonomía e independencia, se producen efectos claramente negativos para las mujeres, por cuanto no se produce ninguna modificación en el reparto del trabajo reproductivo entre sexos, y el trabajo asalariado supone para ellas añadir jornadas de trabajo.

44. En algunos de estos países (Jamaica y Puerto Rico, por ejemplo), se asiste a una clara sustitución de fuerza de trabajo masculina por femenina en los sectores de actividad no agrarios. En el caso de Puerto Rico o México, el reclutamiento de mujeres por parte de las empresas multinacionales ha condenado al paro a los hombres, como consecuencia del declive de la ocupación en la agricultura y en la construcción. Esto explica por qué muchos de estos hombres se ven obligados a emigrar a los Estados Unidos si quieren trabajar y por qué muchas mujeres reemplazan a los hombres como «cabezas de familia» (Sabaté y otros, 1995).

45. Fernández-Kelly (1983) constata que, aunque la migración mexicana hacia los Estados Unidos no es un fenómeno nuevo, su incremento coincide con la proliferación de plantas manufactureras orientadas hacia la exportación («maquilas»), subsidiarias de corporaciones multinacionales lo que ha significado una fuerte corriente migratoria desde el interior de México hacia la frontera con los EE.UU. 


\section{Conclusiones}

La sociedad industrial se ha basado desde sus orígenes en una mercantilización incompleta de la capacidad humana de trabajo y su mantenimiento depende de la situación desigual de hombres y mujeres. Tal como manifiesta Carrasco $(1989,1991)^{46}$, el sistema económico necesita de una producción doméstica que sea asumida por la familia — eufemismo de mujer —, que reduzca enormemente el coste de buena parte del proceso de reproducción social, tanto para el capital como para el Estado. De ese modo, el trabajo doméstico beneficia al mismo tiempo al sistema capitalista y a los sujetos varones. El ámbito doméstico es un área de actividad económica que subsidia la acumulación capitalista a través de la reproducción de la fuerza de trabajo y la producción, el procesamiento y el consumo de bienes. A través del trabajo doméstico no remunerado, los grupos capitalistas permanecen exentos de la necesidad de sufragar los costos de reproducción de la fuerza laboral. El trabajo doméstico no remunerado es el que sostiene la incorporación de los individuos a las labores de subsistencia y/o empleo asalariado.

Por consiguiente, sólo mediante la introducción de la coordenada de género en los estudios sobre desarrollo pueden vincularse dimensiones complementarias de la economía y del desarrollo, gracias a la identificación de una esfera doméstica donde la fuerza de trabajo se reproduce y adquiere la disciplina necesaria para integrarse al trabajo asalariado. Se trata de un instrumento que permite captar la globalidad de los procesos económicos, políticos y sociales que hay detrás del desarrollo, ya que identifica aspectos del sistema productivo que otros conceptos simplemente no tienen en cuenta o explican de forma muy limitada e insuficiente. Cualquier enfoque sobre desarrollo que se pretenda global, debe partir de una concepción del sistema social integrado por una esfera productiva y una esfera reproductiva que coexisten y se influyen mutuamente en un mismo nivel jerárquico. En este sentido, para comprender la situación de hombres y mujeres en la esfera productiva, es necesario conocer cuál es su relación con la esfera reproductiva, aunque sea en términos de ausencia, como en el caso de los hombres (Borderías, Carrasco, 1994).

Pero la participación de las mujeres en el desarrollo no se limita a la asunción de las tareas reproductivas, cuyo volumen crece sin cesar como consecuencia del impacto de la globalización económica en las economías periféricas o en desarrollo. El patriarcado es inherente a las necesidades del capitalismo, de modo que éste último se sirve de la subordinación de las mujeres en beneficio del capital, tanto en la producción doméstica como en la producción capitalista. En otras palabras, el patriarcado es utilizado por sistemas clasistas para ejercer

46. A la misma conclusión llega Wallerstein al asegurar que el sexismo se traduce no sólo en la asignación de «un trabajo diferente o incluso menos apreciado a las mujeres»; sino que, al mismo tiempo, «la aportación de trabajo no asalariado compensa el bajo nivel de los ingresos salariales y, por consiguiente, representa en la práctica una subvención indirecta a los empresarios de los asalariados que pertenecen a esas familias» (1991: 58). 
control sobre poblaciones diferenciadas en base al género (Fernández-Kelly, 1991). Por un lado, el trabajo doméstico permite la reproducción de la mercancía fuerza de trabajo y, en consecuencia, posibilita que los salarios sean más bajos que si fuera menester adquirir todos los bienes y servicios en el mercado. Por el otro, la existencia de un contingente de mujeres relegadas al trabajo doméstico y de cuyas estrategias depende cada vez más la supervivencia de las familias en los países en desarrollo, ofrece la ventaja adicional de disponer de mano de obra barata, flexible y poco conflictiva, susceptible de ser retirada o incorporada al mercado de trabajo según las necesidades de producción. Existe, pues, un claro nexo entre la feminización de las estrategias de supervivencia y la deslocalización industrial (Sassen, 2000; Ribas, 2001).

\section{Bibliografía}

AfSHAR, H. (1999). «Mujeres y desarrollo: una introducción». En: Globalización y género, P. de Villota (ed.). Madrid: Síntesis.

AJAMIL, M. (1999). «Enfoques y estrategias sobre género y desarrollo». En: Globalización y género, P. de Villota (ed.). Madrid: Síntesis.

BAKKER, I. (1999). «Dotar de género a la reforma de la política macroeconómica en la era de la reestructuración y el ajuste global». En: Mujeres y economía, C. Carrasco (ed.). Barcelona: Icaria.

BARRIENTOS, S. (1999). "La mano de obra femenina y las exportaciones globales: mujeres en las agroindustrias chilenas». En: Globalización y género, P. de Villota (ed.). Madrid: Síntesis.

BENERÍA, L. (1981). «Reproducción, producción y división sexual del trabajo». Mientras Tanto, núm. 6, p. 47-83.

- (1991). "La globalización de la economía y el trabajo de las mujeres». Revista de Economía y Sociología del Trabajo, núm. 13-14, p. 23-34.

- (1998). «Karl Polanyi, la construcción del mercado global y la "diferencia" de género». Mientras Tanto, núm. 71: 81-99.

- (1999). «Mercados globales, género y el Hombre de Davos». En: Mujeres y economía, C. Carrasco (ed.). Barcelona: Icaria.

BENERÍA, L.; SEN, G. (1981). «Accumulation, reproduction and women's role in economic development: Boserup revisited». Signs, 7(2).

— (1983). «Desigualdades de clase y de género y el rol de la mujer en el desarrollo económico: implicaciones teóricas y prácticas». Mientras Tanto, núm. 15, p. 91111.

BifANI, P. (1997). «Impacto de la globalización sobre la mujer en América Latina y África Subsahariana». En: Género, clase y etnia en los nuevos procesos de globalización, V. Maquieira y Ma J. Vidal (ed.). Madrid: Instituto Universitario de Estudios de la Mujer y Universidad Autónoma de Madrid.

- (1999). «El impacto de los programas de ajuste estructural en las mujeres africanas». En: Globalización y género, P. de Villota (ed.). Madrid: Síntesis

BORDERÍAS, C.; CARRASCO, C. (1994). «Las mujeres y el trabajo: aproximaciones históricas, sociológicas y económicas». En: Las mujeres y el trabajo, C. Borderías, C. Carrasco y C. Alemany (ed.). Madrid: Fuhem.

Borderías, C.; CARrasco, C.; Alemany, C. (comp.) (1994). Las mujeres y el trabajo. Madrid: Fuhem. 
Boserup, E. (1993). La mujer y el desarrollo económico. Madrid: Minerva (ed. original, 1970).

Brydon, L.; ChAnT, S. (1989). Women in the Thirld World: Gender Issues in Rural and Urban. Cheltenham: Edward Elgar.

Cardoso, F. H.; Faletto, E. (1969). Dependencia y desarrollo en América Latina. México: Siglo Veintiuno.

CARrasCo, C. (1989). "La valoración del trabajo doméstico: un enfoque reproductivo». En: Economía del trabajo femenino, sector mercantil y no mercantil, F. Caillavet (coord.). Madrid: IMU.

- (1991). El trabajo doméstico y la reproducción social. Madrid: IMU.

CASTELLS, M. (1997). La era de la información. Economía, sociedad y cultura. Vol. 1: La sociedad red. Madrid: Alianza.

- (1998). La era de la información. Economía, sociedad y cultura. Vol. 2: El poder de la identidad. Madrid: Alianza.

CoHen, R. (ed.) (1996). Theories of Migration. Cheltenham: Edward Elgar Publishing.

Coltrane, S.; Galt, J. (2000). «The History of Men's Caring». En: Care Work, Gender Labor and Welfare State, M. Harrington (ed.). Nueva York: Routledge.

Croff, B. (1996). "Les emplois familiaux: le travail domestique rehabilité». Les Cahiers du Mage, vol. 4.

CRUZ C., DE LA (1999). "Globalización de la economía y justicia económica. En: Globalización y género, P. de Villota (ed.). Madrid: Síntesis.

FERNÁNDEZ ENGUITA, M. (1989). «La degradación del trabajo doméstico». En: Economía del trabajo femenino, sector mercantil y no mercantil, F. Caillavet (coord.). Madrid: IMU.

FERNÁNDEZ KeLlY, Ma P. (1991). «Desarrollo económico y participación de las mujeres: Viejos problemas, nuevos debates». En: Teorías del desarrollo nacional, A. Portes (comp.). San José (USA): Educa.

FNUAP (1993). Estado de la población mundial, 1993. Nueva York: FNUAP Fondo de Población de las Naciones Unidas.

FrÖBEL, F. y otros (1980). The New International Division of Labour. Cambridge: University Press.

FULLER, N. (1999). «¿Pobreza o desigualdad de género?: El caso de las familias jefaturadas por mujeres». Anuario de Hojas de Warmi, núm. 10, p. 43-59.

GONZÁLEZ, Ma J. (2001). «Algunas reflexiones en torno a las diferencias de género y la pobreza». En: Pobreza y perspectiva de género, J. Ma Tortosa (ed.). Barcelona: Icaria.

GroizARD, J. L. (1996). "Las empresas transnacionales en el final de siglo». África América Latina. Cuadernos, núm. 26, p. 43-58.

GUNDER FRANK, A. (1991). El desarrollo del subdesarrollo. Madrid: Iepala.

HernándeZ, I. (1999). "Desigualdad de género en desarrollo». En: Globalización y género, P. de Villota (ed.). Madrid: Síntesis.

IMU (1987). Estrategias de Nairobi orientadas hacia el futuro para el adelanto de la mujer. Madrid: IMU.

- (1997). La larga marcha hacia la igualdad. IV conferencia mundial sobre las mujeres. Beijing 95. Madrid: Instituto de la Mujer.

LEWIS, W. A. (1969). Some aspects of economic development. Londres: George Allen \& Unwin.

Lim, L. (1983). «Capitalism, Imperialism and Patriarchy: the Dilemma of Third-World Women Workers in Multinational Factories». En: Women, Men and the Interna- 
tional Division of Labour, J. Nash y M. P. Fernandez-Kelly (ed.). Nueva York: State University Press.

LÓPEZ, Ma A. (1997). «Efectos de las políticas de ajuste estructural en la situación de las mujeres magrebíes». En: Género, clase y etnia en los nuevos procesos de globalización, V. Maquieira y $\mathrm{M}^{\mathrm{a}} \mathrm{J}$. Vidal (ed.). Madrid: Instituto Universitario de Estudios de la Mujer y Universidad Autónoma de Madrid.

LunA, L. G. (1999). «La relación de las mujeres y el desarrollo en América Latina: apuntes históricos de dos décadas 1975-1995». Anuario de Hojas de Warmi, núm. 10, p. 61-78.

Macionis, J. J.; Plummer, K. (2000). Sociología. Madrid: Prentice Hall.

MarTínez VeIgA, U. (1997). La integración social de los inmigrantes en España. Madrid: Trotta.

MARUANI, M. y otros (dir.) (2000). Las nuevas fronteras de la desigualdad. Barcelona: Icaria.

MASSOLO, A. (1999). «Las mujeres y el hábitat popular: ¿cooperación para la sobrevivencia o para el desarrollo?». Anuario de Hojas de Warmi, núm. 10, p. 79-89.

Meulders, D. (2000). «La flexibilidad en Europa». En: Las nuevas fronteras de la desigualdad, M. Maruani y otros (ed.). Barcelona: Icaria.

Momsen, J. H. (ed.) (1991). Women and Development in the Third World. Londres: Routledge.

Momsen. J. H. (1991). «Maids on the move». En: Women and Development in the Third World, J. H. Momsen (ed.). Londres: Routledge.

MoOre, H. L. (1999). Antropología y feminismo. Madrid: Cátedra.

MOROKVASIC, M. (1993). "In and out" of the labour market: Immigrant and minority women in Europe». New Community, 19(3), p. 459-483.

Nash, J.; FernandeZ-Kelly, M. P. (1983). Women, Men and the International Division of Labor. Nueva York: State University Press.

PEARSON, R. (1999). "El género cuenta en el desarrollo». En: Mujeres y economía, C. Carrasco (ed.). Barcelona: Icaria.

PeÑA, E. (2001). «La inmigración femenina». En: Globalización a qué precio, P. de Villota (ed.). Barcelona: Icaria.

PhizackleA, A. (1999). "Gender and Transnational Labour Migration». En: Ethnicity, Gender and Social Change, Barot y otros (ed.). Londres: Macmillan.

PNUD (1995). Informe sobre desarrollo humano 1995. Madrid: Mundi Prensa, 1995. PORTES, A. (1991). "Sociología y desarrollo en los años 90. Desafíos críticos y tendencias empíricas». En: Teorías del desarrollo nacional, A. Portes (comp.). San José (USA): Educa.

- (1991) (comp.). Teorías del desarrollo nacional. San José (USA): Educa.

RiBAS, N. (2001). «¿Estrategias transnacionales? Una pregunta acerca de las migraciones femeninas en España». Arxius. Arxius de ciències socials, núm. 5, p. 69-92.

RifKIN, J. (1996). El fin del trabajo. Barcelona: Paidós.

SABATÉ. A. y otros (1995). Mujeres, espacio y sociedad. Hacia una geografía del género. Madrid: Síntesis.

SAFA, H. I. (1984). «Female Employment and the Social Reproduction of the Puerto Rican Working Class». International Migration Review, vol. 18, núm. 4, p. 11681187.

SASSEN, S. (1984). «Notes on the Incorporation of Third World Women into WageLabor Through Immigration and Off-Shore Production». International Migration Review, vol. 18, núm. 4, p. 1144-1165. 
SASSEN, S. (1993). La movilidad del trabajo y del capital. Madrid: Ministerio de Trabajo y Seguridad Social.

- (1998). Globalization and Its Discontents. Nueva York: The New Press.

- (2000). "Women's Burden: Countergeographies of Globalization and Feminization of Survival». Journal of International Affairs, primavera 2000, p. 503-524.

SKLAIR, L. (1995). Sociology of the Global System. Baltimore: The Johns Hopkins University Press.

Solé, C. (1998). Modernidad y modernización. Barcelona: Anthropos.

TeZAnos, J. F. (2001). El trabajo perdido. ¿Hacia una civilización postlaboral? Madrid: Biblioteca Nueva.

Tienda, M.; BoOTH, K. (1991). "Gender, Migration and Social Change». International Sociology, vol. 6. núm. 1, p. 51-72.

TORTOSA, J. Ma. (2001). Pobreza y perspectiva de género. Barcelona: Icaria.

VIDAL VILLA, J. Ma . (1995). Cap a una economia mundial. Nord-Sud cara a cara. Barcelona: Universitat de Barcelona.

Villota DE, P. (ed.) (1999). Globalización y género. Madrid: Síntesis.

WALBY, S. (2000). «Figuras emblemáticas del empleo flexible». En: Las nuevas fronteras de la desigualdad, M. Maruani y otros (ed.). Barcelona: Icaria.

WALLERSTEIN, I. (1979). El moderno sistema mundial. Madrid: Siglo XXI.

- (1991). "Universalismo, racismo y sexismo, tensiones ideológicas del capitalismo». En: Raza, nación y clase, E. Balibar y I. Wallerstein (ed.). Madrid: Iepala.

Willis, K.; YeOH, B. (ed.) (1999). Gender and Migration. Cheltenhom: Edward Elgar. Willis, K.; YeOH, B. (1999). "Introduction». En: Gender and Migration, K. Willis y B. Yeoh (ed.). Cheltenham: Edward Elgar.

Wood, C. (1992). «Modelos opuestos en el estudio de la migración». Alfoz, núm. 9192, p. 35-59.

Zabala, I. (1999). «Un viaje a través del tiempo: 30 años de pensamiento económico feminista en torno al desarrollo». En: Mujeres y economía, C. Carrasco (ed.). Barcelona: Icaria.

ZolberG, A. R. (1983). «The Next Waves: Migration Theory for a Changing World». En: Theories of Migration, R. Cohen (ed.). 1996. Cheltenham: Edward Elgar Publishing. 